\title{
Trace Solvent as a Predominant Factor to Tune Dipeptide
}

\section{Self-Assembly}

Juan Wang ${ }^{\dagger, \ddagger}$, Kai Liu ${ }^{\dagger, \ddagger, \S}$, Linyin Yan ${ }^{\dagger, \ddagger}$, Anhe Wang ${ }^{\dagger}$, Shuo Bai ${ }^{\dagger}$, and Xuehai Yan ${ }^{*,+, \ddagger}$

${ }^{\dagger}$ National Key Laboratory of Biochemical Engineering, Institute of Process Engineering, Chinese Academy of Sciences, Beijing 100190, P.R. China

${ }^{\ddagger}$ Center for Mesoscience, Institute of Process Engineering, Chinese Academy of Sciences, Beijing 100190, P.R. China

${ }^{\S}$ University of Chinese Academy of Sciences, Beijing 100049, P.R. China

*Address correspondence to Email: yanxh@ipe.ac.cn

Homepage: http://www.yan-assembly.org/ 
Table S1. Classification of solvents

\begin{tabular}{ccc}
\hline Type of solvents & Solvents & Interactions with FF \\
\hline I & Ethanol & hydrogen-bond \\
& DMF & \\
II & Acetone & $\pi-\pi$ interactions \\
III & Toluene & Van der Waals interactions \\
\hline
\end{tabular}



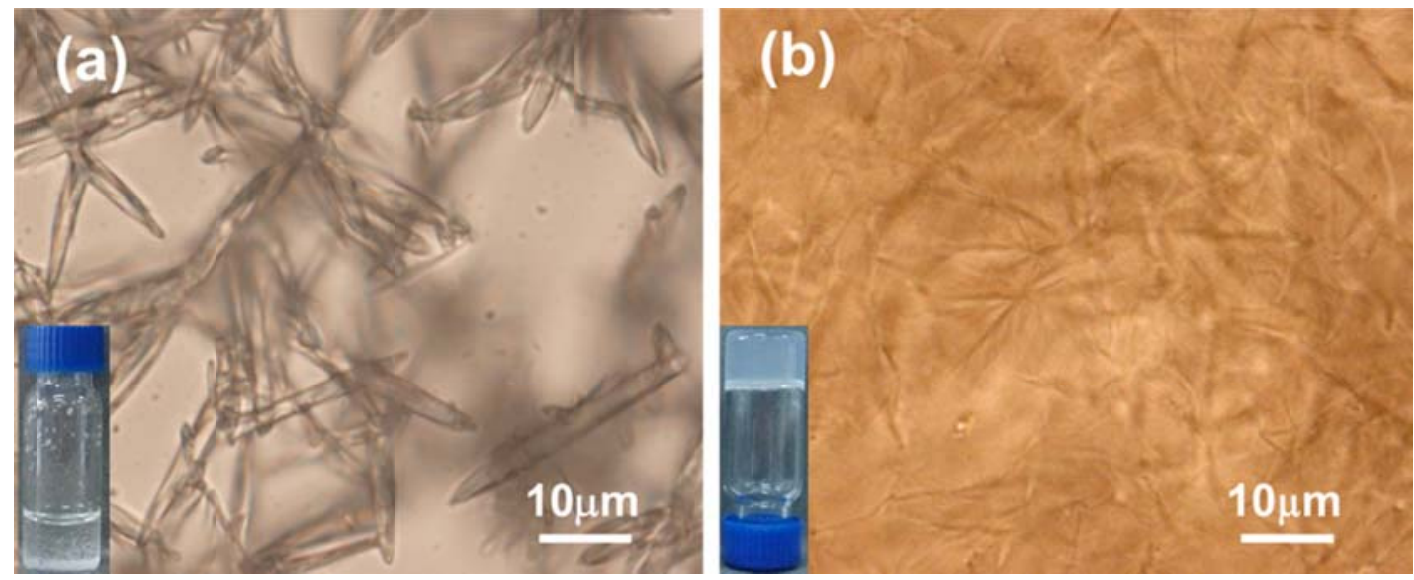

Figure S1. Solution-based optical microscope images of (a) microcrystals $\left(\mathrm{FF} / \mathrm{CH}_{2} \mathrm{Cl}_{2}\right.$ system) and (b) gel (FF/CH $\mathrm{Cl}_{2} /$ ethanol system with ethanol content of 3\%). The insets show photos of these systems. 

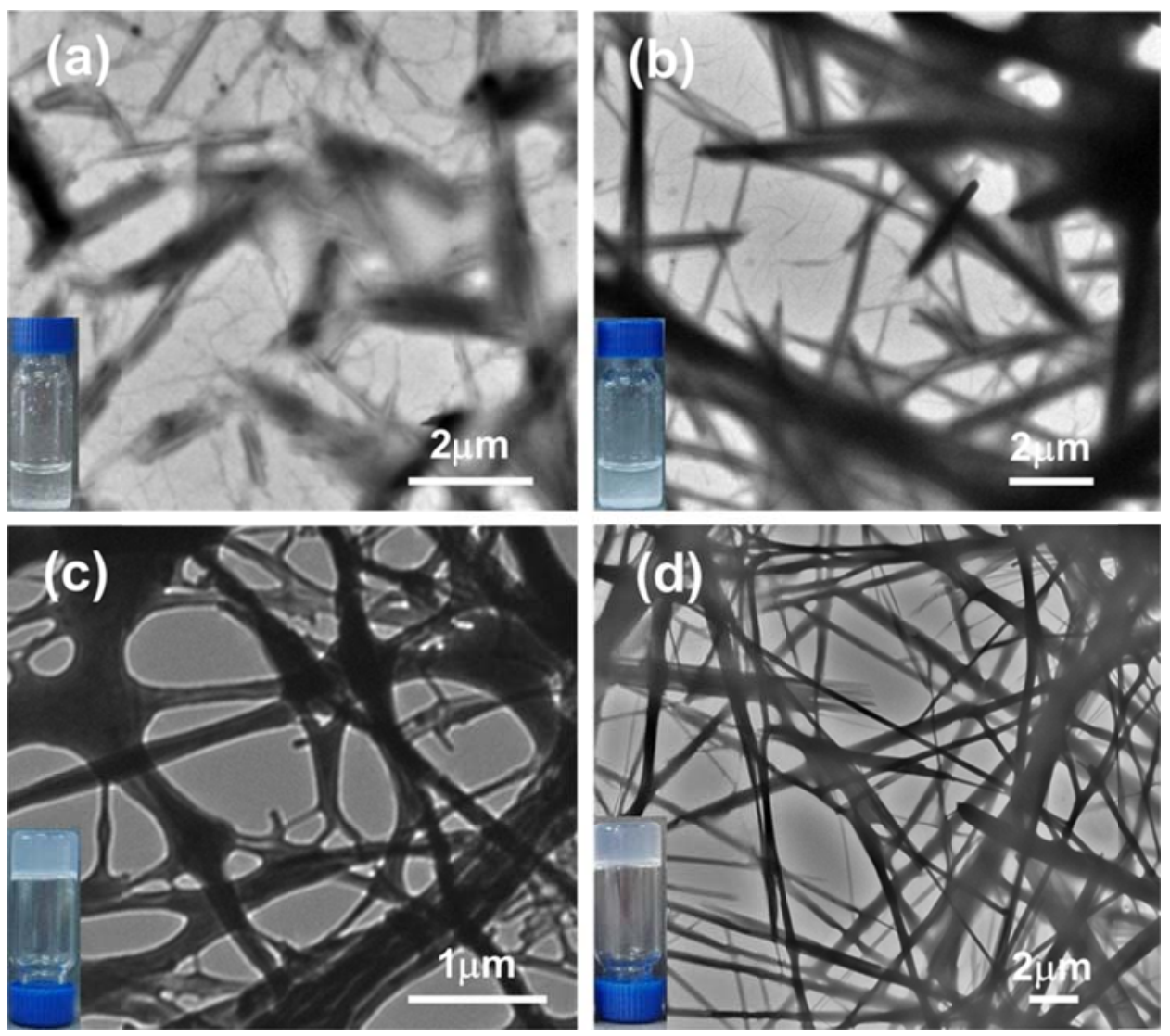

Figure S2. TEM images of $\mathrm{FF} / \mathrm{CH}_{2} \mathrm{Cl}_{2} /$ ethanol systems with ethanol contents (a) $0 \%$, (b) $1 \%$, (c) $3 \%$, and (d) $5 \%$. The insets show photos of these systems. 

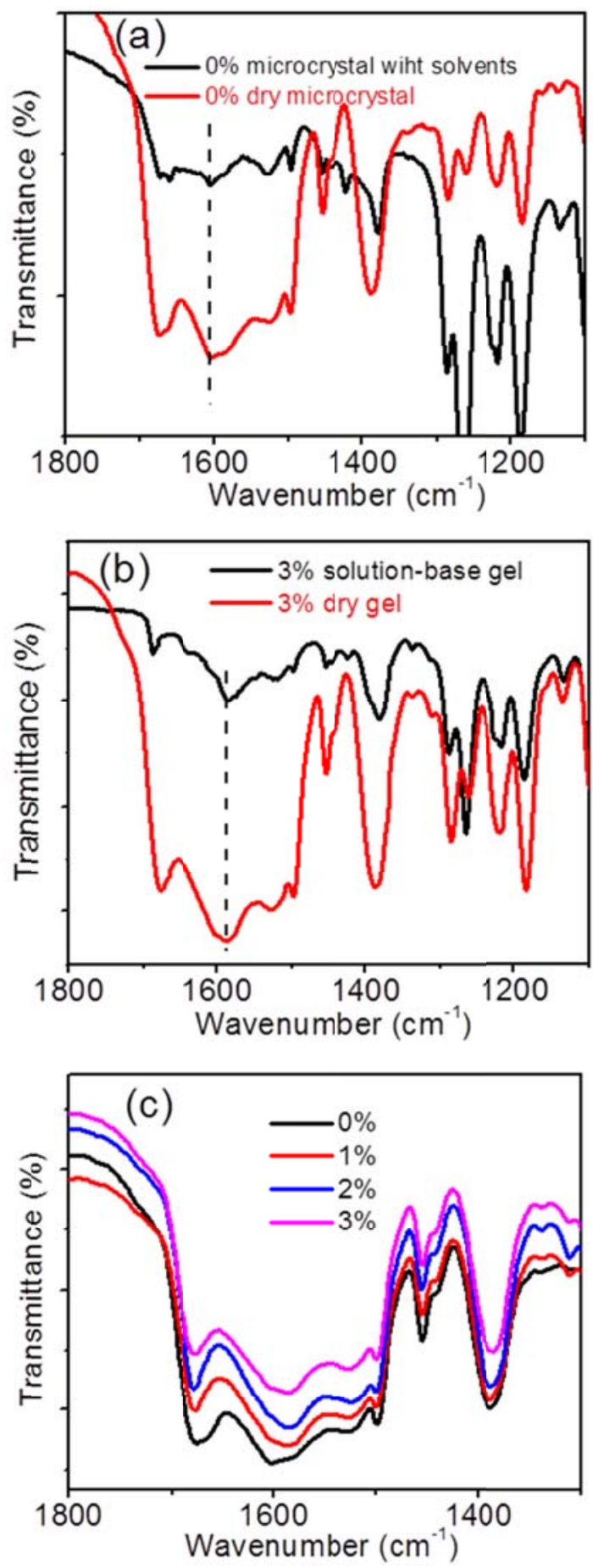

Figure S3. Comparision of FTIR spectra between solution-based and dried samples of $\mathrm{FF} / \mathrm{CH}_{2} \mathrm{Cl}_{2} /$ ethanol systems with ethanol content (a) $0 \%$, and (b) $3 \%$. FTIR spectra of dried $\mathrm{FF} / \mathrm{CH}_{2} \mathrm{Cl}_{2} /$ ethanol with different ethanol content (c). 

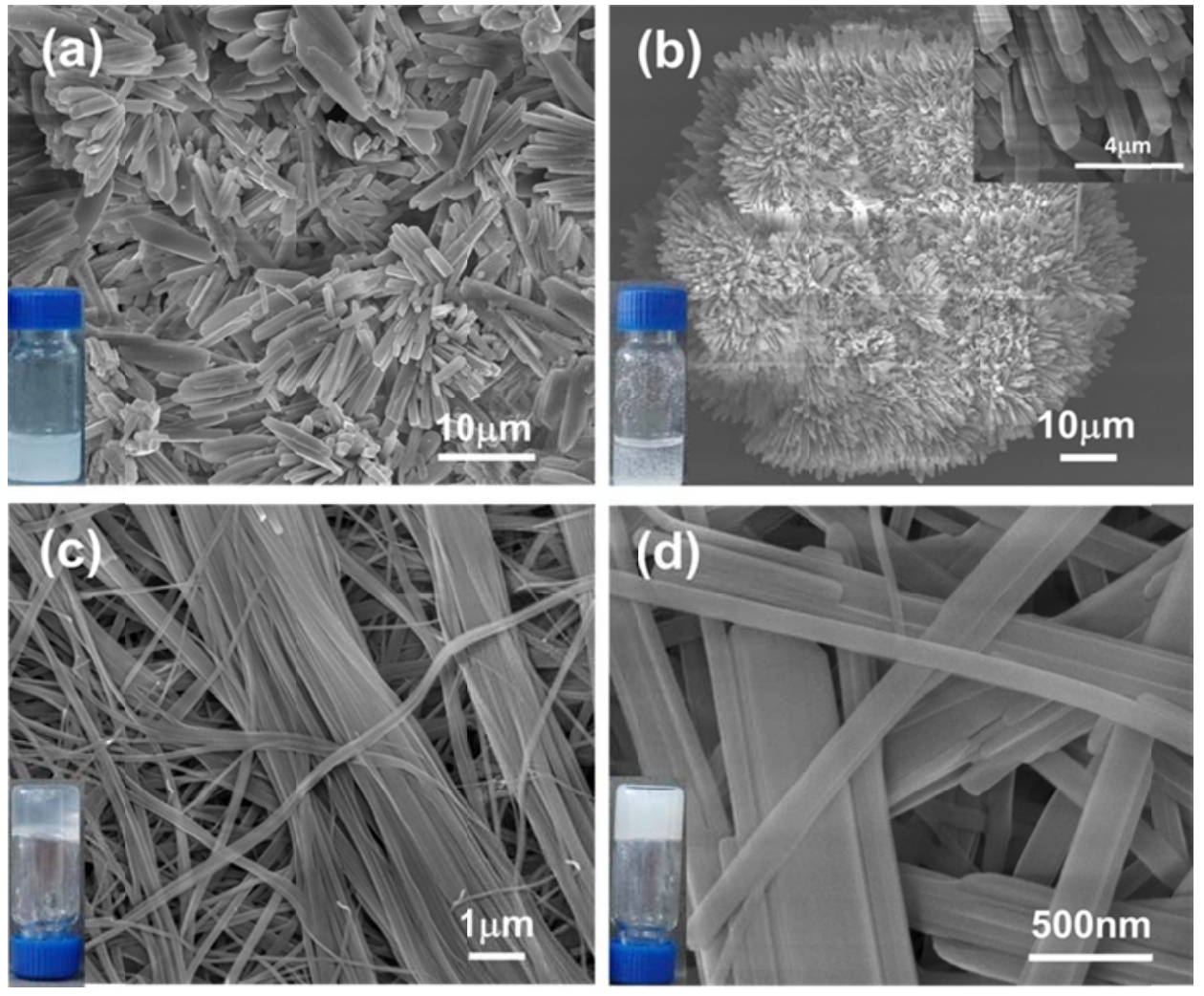

Figure S4. SEM images of $\mathrm{FF} / \mathrm{CH}_{2} \mathrm{Cl}_{2} /$ ethanol/water systems with different water content.

The ethanol/water content in dichloromethane is fixed at $2 \%$, but the ratios of water to ethanol are 0:1 (a), 1:19 (b), 1:9 (c), and 1:4 (d). The insets show photos of these systems. 

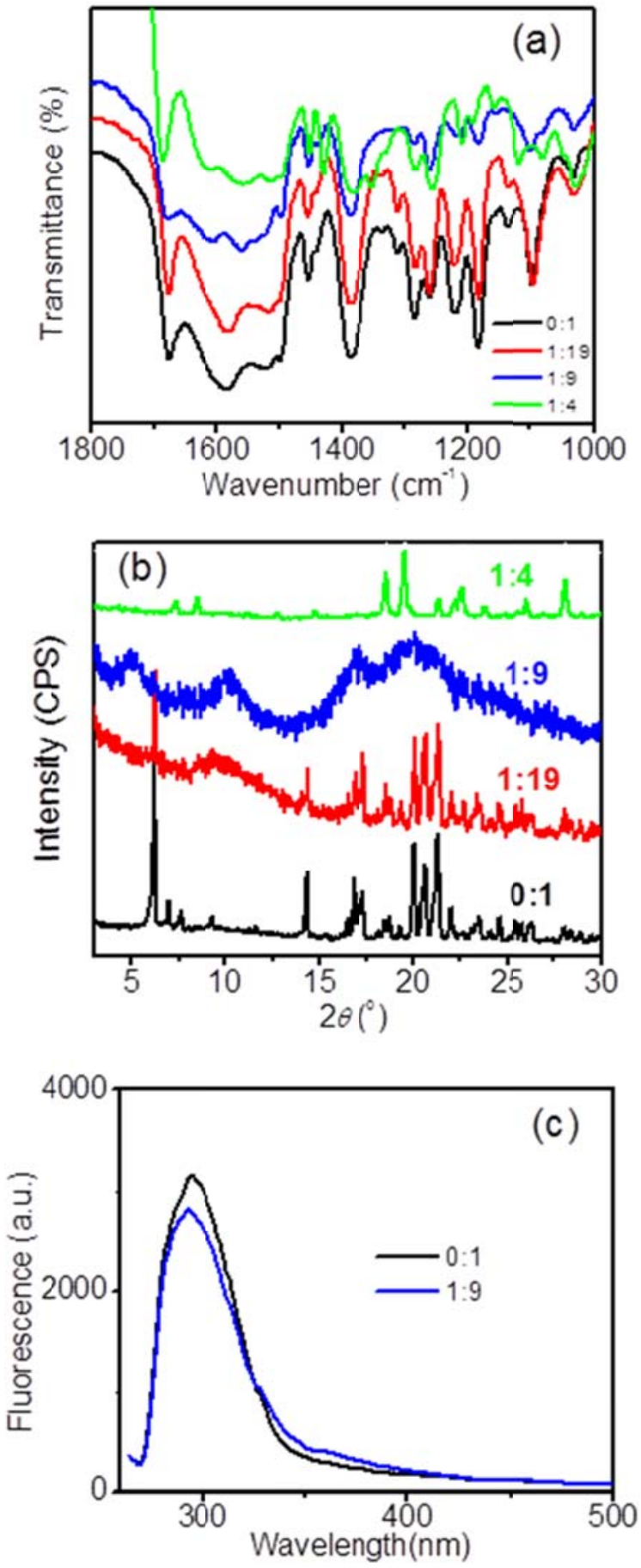

Figure S5. (a) FTIR spectra, (b) XRD patterns, and (c) FL spectra $\left(\lambda_{\text {excitation }}=259 \mathrm{~nm}\right)$ of $\mathrm{FF} / \mathrm{CH}_{2} \mathrm{Cl}_{2} /$ ethanol/water systems. The ethanol/water content in dichloromethane is fixed at $2 \%$, but the ratios of water to ethanol are $0: 1,1: 19,1: 9$, and 1:4. 

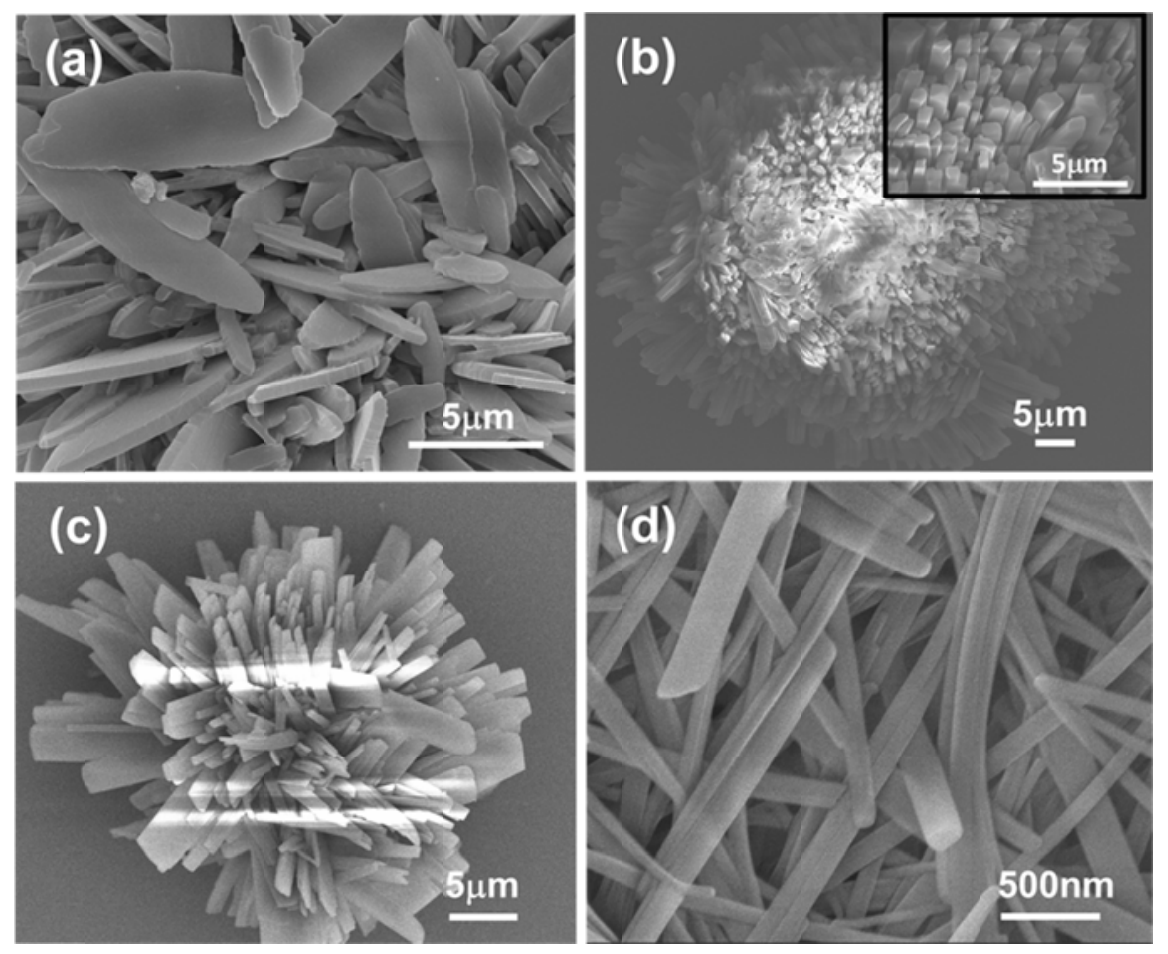

Figure S6. SEM images of $\mathrm{FF} / \mathrm{CH}_{2} \mathrm{Cl}_{2} /$ ethanol/water systems with different water content.

The ethanol/water content in dichloromethane is fixed at $1 \%$, but the ratios of water to ethanol are 0:1 (a), 1:19 (b), 1:9 (c), and 1:4 (d). 

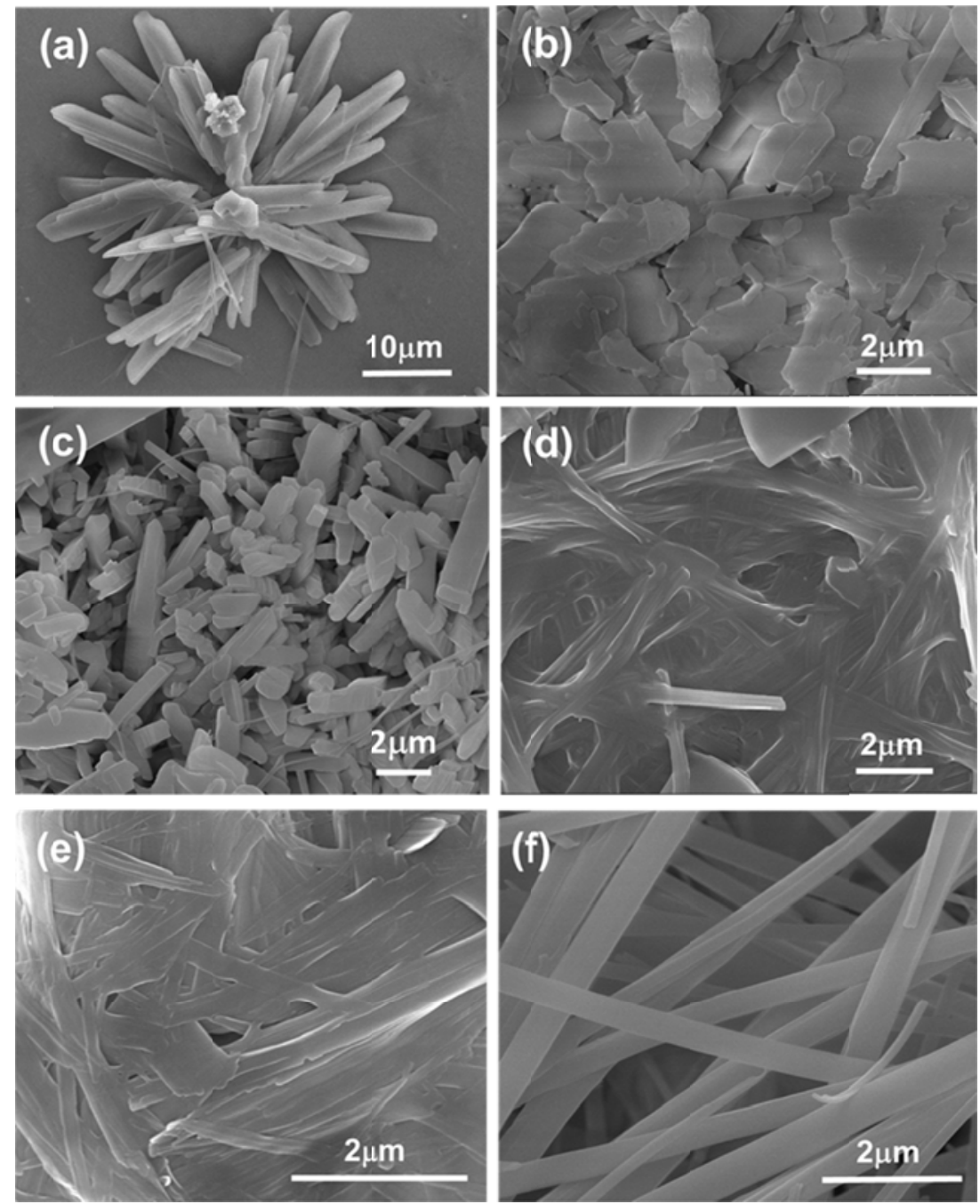

Figure S7. SEM images of FF/ $\mathrm{CH}_{2} \mathrm{Cl}_{2} / \mathrm{DMF}$ systems with DMF contents (a) $0 \%$, (b) $0.5 \%$, (c) $1 \%$, (d) $2 \%$, (e) $3 \%$, and (f) $5 \%$. 

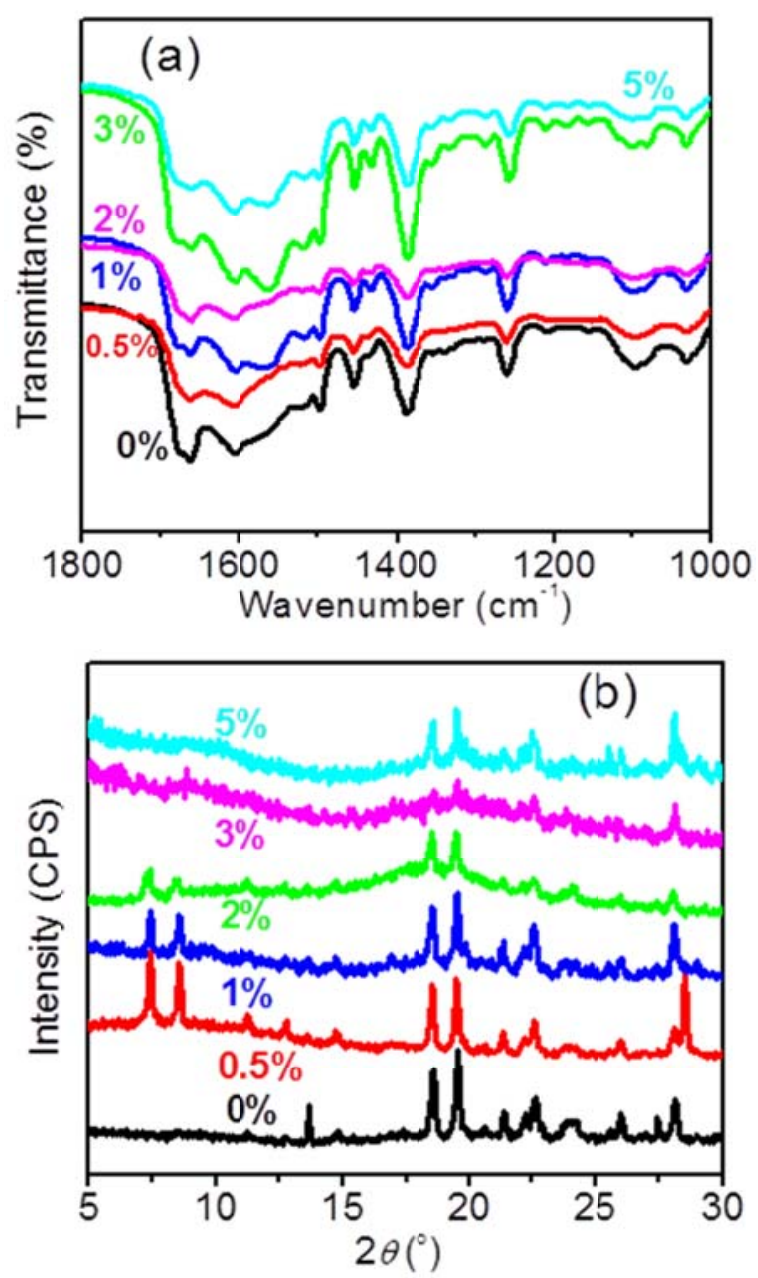

Figure S8. (a) FTIR spectra, and (b) $\mathrm{XRD}$ patterns of $\mathrm{FF} / \mathrm{CH}_{2} \mathrm{Cl}_{2} / \mathrm{DMF}$ systems with different DMF content.

FTIR spectra of FF in pure dichloromethane show a strong amide I absorption band (vibration of $\mathrm{C}=\mathrm{O}$ ) in the vicinity of $1659 \mathrm{~cm}^{-1}$ and an amide II absorption band (in-plane vibration of $\mathrm{N}-\mathrm{H}$ ) nearby $1605 \mathrm{~cm}^{-1}$, indicating a hydrogen-bonded $\beta$-sheet secondary structure. When trace DMF was added, a new peak appeared at $1560 \mathrm{~cm}^{-1}$. 

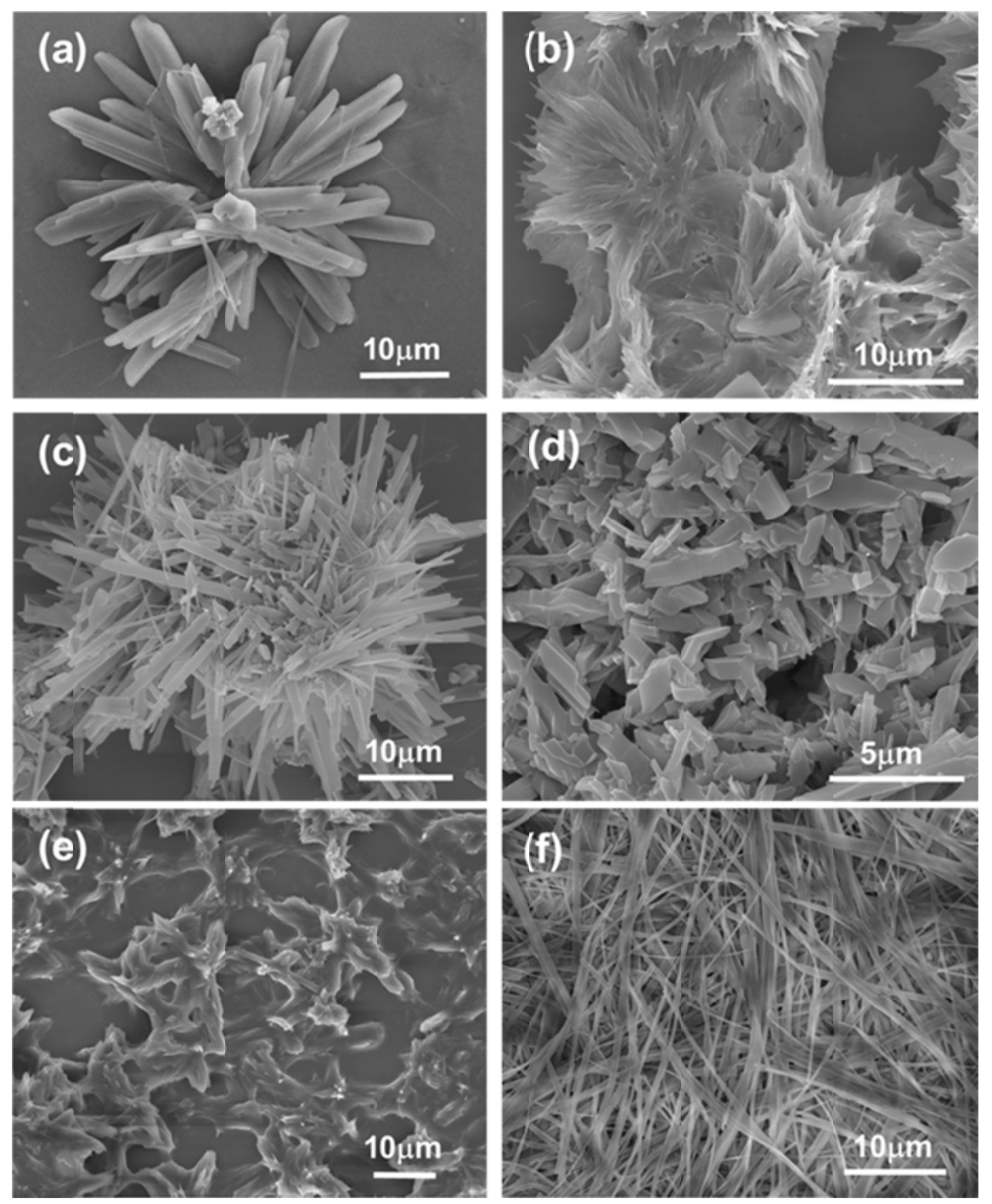

Figure S9. SEM images of $\mathrm{FF} / \mathrm{CH}_{2} \mathrm{Cl}_{2} /$ acetone systems with acetone contents (a) $0 \%$, (b) $0.5 \%$, (c) $1 \%$, (d) $2 \%$, (e) $3 \%$, and (f) $5 \%$. 

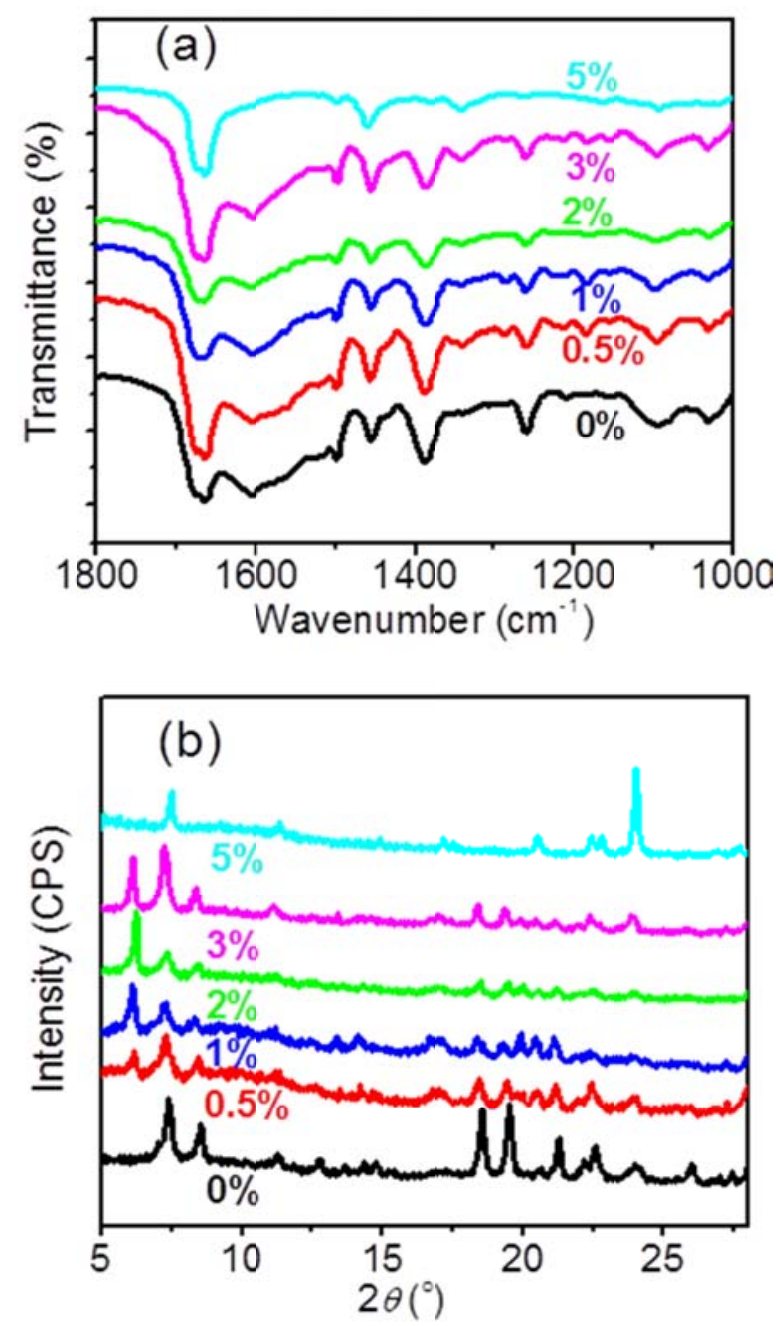

Figure S10. (a) FTIR spectra, and (b) XRD patterns of $\mathrm{FF} / \mathrm{CH}_{2} \mathrm{Cl}_{2} /$ acetone systems with different acetone content.

FTIR spectra of FF in pure dichloromethane show a strong amide I absorption band (vibration of $\mathrm{C}=\mathrm{O}$ ) in the vicinity of $1665 \mathrm{~cm}^{-1}$ and an amide II absorption band (in-plane vibration of $\mathrm{N}-\mathrm{H}$ ) nearby $1606 \mathrm{~cm}^{-1}$, indicating a hydrogen-bonded $\beta$-sheet secondary structure. When trace acetone was added, the peak at $1606 \mathrm{~cm}^{-1}$ in the $5 \%$ system disappeared. 

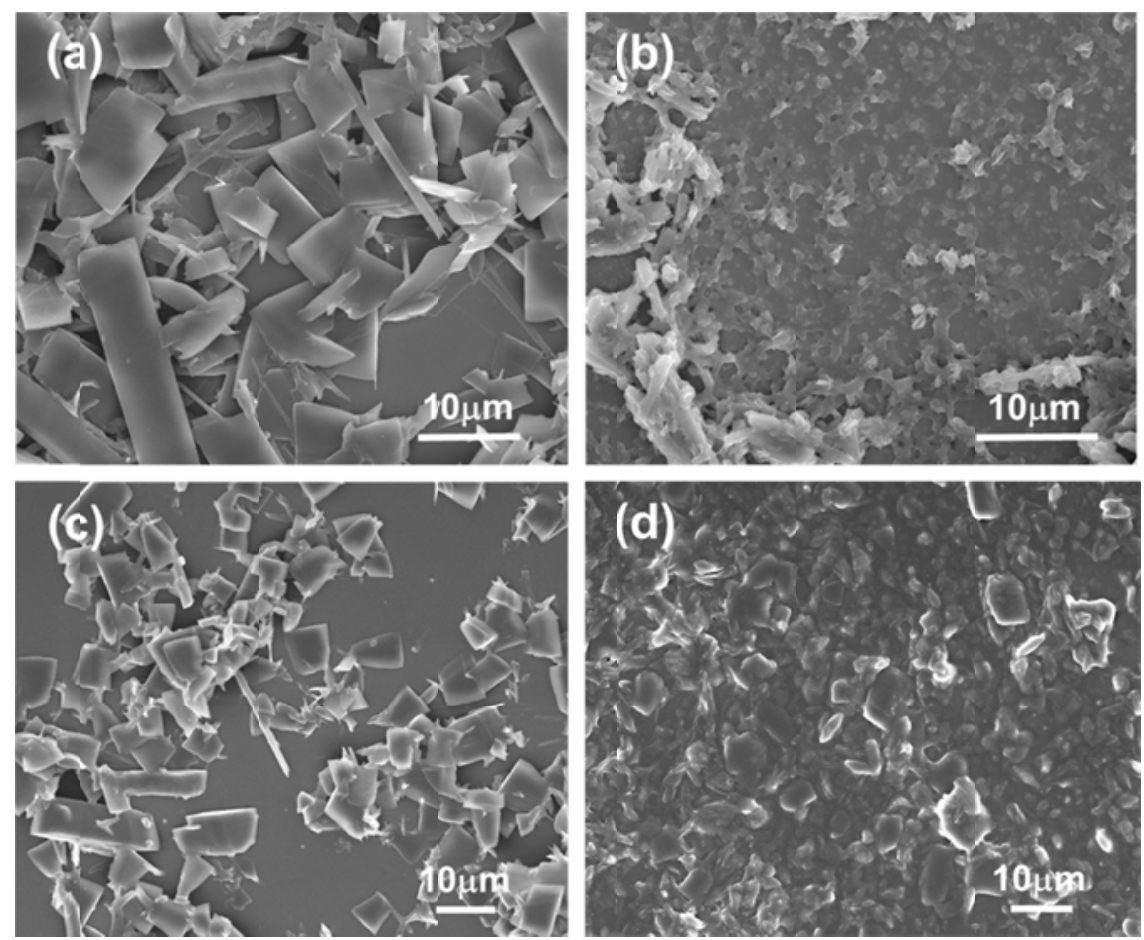

Figure S11. SEM images of $\mathrm{FF} / \mathrm{CH}_{2} \mathrm{Cl}_{2}$ /toluene systems with different toluene contents (a) $2 \%$, (b) $5 \%$, and $\mathrm{FF} / \mathrm{CH}_{2} \mathrm{Cl}_{2} / n$-hexane systems with different $n$-hexane contents (c) $2 \%$, (d) $5 \%$. 

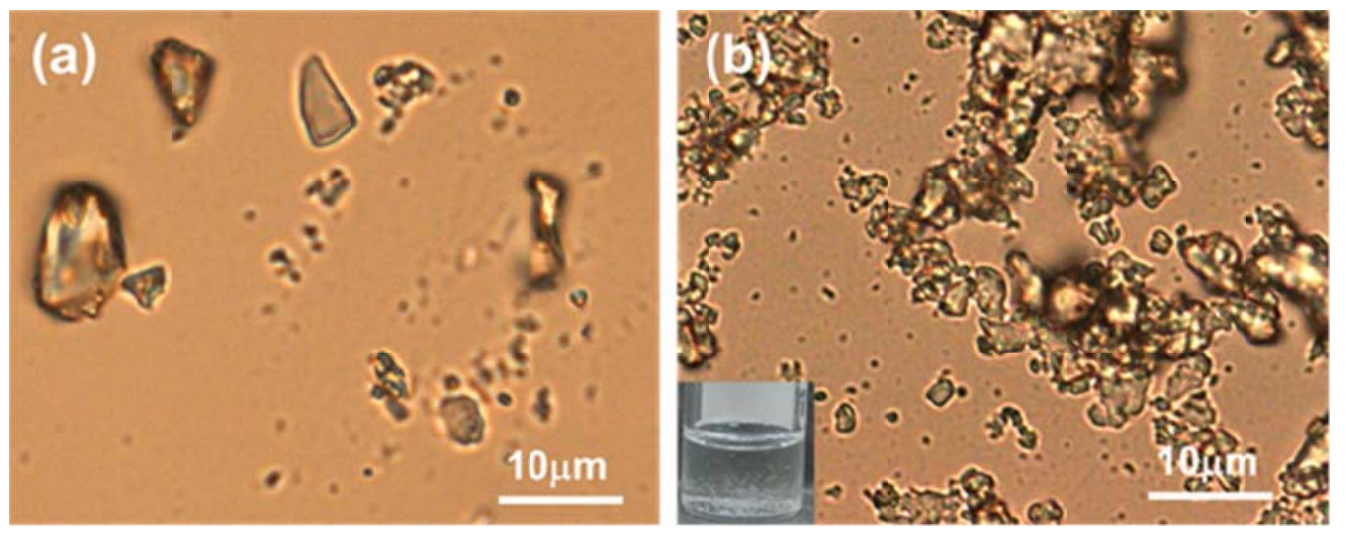

Figure S12. Optical microscopy images of $\mathrm{FF} / \mathrm{CH}_{2} \mathrm{Cl}_{2} /$ toluene systems with different toluene content, (a) 10\%, and (b) 15\%. 


\section{Method of Density-functional-theory (DFT) simulation:}

All computations were carried out at the B3LYP level of theory with the Gaussian 09 computer code. ${ }^{1}$ The B3LYP functional is a widely used density functional in quantum chemistry, which performs very well for a broad spectrum of chemical problems. ${ }^{2,3}$ The 6-31G(d,p) basis set has been used for geometry optimization. ${ }^{4,5}$ Frequency calculations were performed to verify the minima nature of reactant and product. Four FFs and four ethanol molecules have been chosen. As for the hydrogen bond, ethanol could act as both donor and acceptor. The inter-molecular hydrogen bonds network among FFs has been significantly enhanced by ethanol.

\section{Reference}

1. Revision D.01 Gaussian 09, Frisch, M. J.; Trucks, G. W.; Schlegel, H. B.; Scuseria, G. E.; Robb, M. A.; Cheeseman, J. R.; Scalmani, G.; Barone, V.; Mennucci, B.; Petersson, G. A.; Nakatsuji, H.; Caricato, M.; Li, X.; Hratchian, H. P.; Izmaylov, A. F.; Bloino, J.; Zheng, G.; Sonnenberg, J. L.; Hada, M.; Ehara, M. et al., Gaussian, Inc., Wallingford CT, 2009.

2. Becke, A. D. Density-Functional Thermochemistry .3. The Role of Exact Exchange, $J$. Chem. Phys. 1993, 98, 5648-5652.

3. Lee, C. T.; Yang, W. T.; Parr, R. G. Development of the Colle-Salvetti Correlation-Energy Formula into a Functional of the Electron-Density, Phys. Rev. B, 1988, 37, 785-789.

4. Frisch, M. J.; Pople, J. A.; Binkley, J. S. Self-Consistent Molecular-Orbital Methods .25. 
Supplementary Functions for Gaussian-Basis Sets, J. Chem. Phys. 1984, 80, 3265-3269.

5. Krishnan, R.; Binkley, J. S.; Seeger, R.; Pople, J. A. Self-Consistent Molecular-Orbital Methods.20. Basis Set for Correlated Wave-Functions, J. Chem. Phys. 1980, 72, 650-654. 